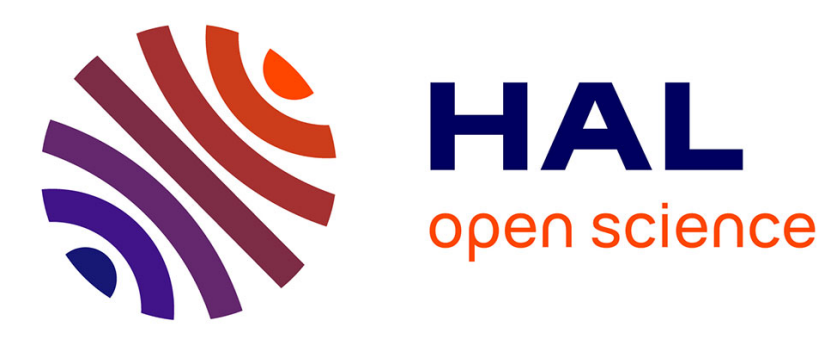

\title{
How to design and process brand identity through an integrated innovative approach
}

\author{
Nattapong Kongprasert, Daniel Brissaud, Carole Bouchard, Ameziane \\ Aoussat, Suthep Butdee
}

\section{To cite this version:}

Nattapong Kongprasert, Daniel Brissaud, Carole Bouchard, Ameziane Aoussat, Suthep Butdee. How to design and process brand identity through an integrated innovative approach. 2008 IEEE International Conference on Industrial Engineering and Engineering Management, Dec 2008, Singapore, Singapore. pp.60. hal-00402618

\section{HAL Id: hal-00402618 https://hal.science/hal-00402618}

Submitted on 7 Jul 2009

HAL is a multi-disciplinary open access archive for the deposit and dissemination of scientific research documents, whether they are published or not. The documents may come from teaching and research institutions in France or abroad, or from public or private research centers.
L'archive ouverte pluridisciplinaire HAL, est destinée au dépôt et à la diffusion de documents scientifiques de niveau recherche, publiés ou non, émanant des établissements d'enseignement et de recherche français ou étrangers, des laboratoires publics ou privés. 


\title{
How to design and process brand identity through an integrated innovative approach
}

\author{
N. Kongprasert ${ }^{1}$, D. Brissaud ${ }^{1}$, C. Bouchard ${ }^{2}$, A. Aoussat $^{2}$, S. Butdee ${ }^{3}$ \\ ${ }^{1}$ G-SCOP, University of Grenoble (Grenoble-INP), Grenoble, France \\ ${ }^{2}$ Product Design and Innovation Laboratory, Art et Metiers PARISTECH, Paris, France \\ ${ }^{3}$ Integrated Manufacturing System Research Center (IMSRC), Department of Production Engineering, \\ King Mongkut's University of Technology North Bangkok, Bangkok, Thailand \\ (E-mail: nattapong.kongprasert@g-scop.inpg.fr )
}

\begin{abstract}
Presently, the leather goods industry in Thailand is facing a severe competition. According to customers the quality and image of products from Thailand are dissatisfying. Thai products often not meet customer satisfactions and requirements mainly due to lack of identity. The research aims to evaluate the brand identity to semantics and presence of design elements, and to validate the perceived message according to what is expressed in product advertising associated with the perception of customers. This paper focuses on the analysis of customers' perception after the detailed design of the product. It includes 2 phases. The first phase aims to explore the customers' perception to product visual form of luxurious brand. The second phase aims to explore the design elements with express brand identity. This approach will lead further study in order to improving the design expression through specific design elements.
\end{abstract}

Keywords - brand identity, semantic analysis, principle component analysis, design process

\section{INTRODUCTION}

Emotion is crucial for everyday decision making [1]. Emotions mainly are conveyed through the semantics of an object. They follow a complex process including how the visual stimulus answers to customers' values, but also attributes and design elements. Consumers' satisfaction relies on desires more than needs [2], where desire is mainly depending on aesthetic, semantic and symbolic aspects of cognitive response to design, including also intrinsic properties like sustainable design [3]. Form and identity of product are largely constructed through visual recognition and brand-specific associations, which dominate the first impression and affect user's feeling when using the product [4]. Warell et al. [5] transfer identity to the domain product design. First, they define identity as an attribute of a thing, which is shared with something else (i.e., 'similarity'); on the second, identity is seem as a unique attribute of a thing (i.e., 'dissimilarity'). Brand identity involves the key identity attributes of the company in a "condensed" form. It express the values of the brand with their form. The principle mission of brand identity is to foster recognition [6]. Brand identity is often expressed by the companies in terms of values. It will be investigated how the semantic can convey some values fitting with customers' one.
Indeed the designer should know what the customer wants? And also what the brand identity is?

Nowadays the leather goods industry in Thailand is facing a severe competition. According to customers the quality and image of products from Thailand are dissatisfying. The products often not meet customer satisfactions and requirements, mainly due to the lack of identity. In order for Thai companies to compete with foreign competitors, it is necessary to adopt a design strategy coping with higher quality, reduced delays and above all closer matching to consumer values. This research takes part in the project Bangkok Fashion City project, which aims at optimizing product design and process with a major objective: the proposition of attractive design solutions to customers through the optimization of the brand image and of the environmental quality. This research focuses on how to evaluate the brand image for further improving the design expression. This study has two goals. First of all, the brand identity phenomenon is studied by comparing Thai and French consumers' perception towards products. It is based on statistical methods to extract semantic values through the adjectives associated with the product. The second is to understand the connection of the semantic adjectives and the design elements and therefore to connect the identity expression to product parameters. Data are statistically analysed by the principle components analysis (PCA) approach. The results obtained enable to visualize the semantic position of products and how this position fits the values of the brand. It helps designers to predict the potential behaviour of customers in front of their new products.

\section{THE STATE OF THE ART}

The state of the art was achieved in the fields of product design and brand identity.

1) Product Design: The visual appearance of products is a critical determinant of consumer response and product success. Judgements are often made on the elegance, functionality and social significance of products based largely on visual information that relate to the perceived attributes of products and frequently centre on the satisfaction of consumer wants and desires, rather than their needs [2]. Emotion design is product design targeted to satisfy customers' subjective requirements. By 
controlling certain design factors, customers' emotion can be evaluated, designed, and satisfied [7]. Kansei Engineering (KE) was founded at Hiroshima University about 30 years ago. It aimed at the implementation of the customer's feeling and demands into product function and design. Kansei engineering, as a kind of human ergonomic technology, can be defined as a methodology for translating human psychological processes such as feeling and emotion related to products into appropriate product design elements such as size, shape, and color [8]. Currently more and more models enabling stylistic innovation are proposed, which are based on the definition of design rules and their translation into product parameters [9]. Chang et al. [10] proposed five expression modes commonly used by consumers when attempting to convey their desires for product form. McDonagh et al. [11] presented product personality profiling for evaluation mood boards and visual product evaluation. Related research advances are well covered by the field of Kansei Engineering. These algorithms aim to partly digitize the product development through an improved iterative styling evaluation and generation process [12]. Schutte and Eklund [13] have been led concept of Kansei Engineering to apply with car design [13].

2) Brand identity: Brands also play an important role in the decision making processes of business customers, acting as a tool for achieving organizational consensus among the many actors involved in the buying process [14]. The brand name, logo and slogan are a key element of a brand's identity, and contribute to a brand's equity. They enhance a brand's image, aid in its recognition and recall, and help create brand differentiation in consumers' minds [15]. The brand identity is a combination of factors, none of which can be unknown, the products themselves express the values of the brand with their form [16]. The principle mission of brand identity is to foster recognition. During last several years, many researchers studied about product and brand identity. Warell et al. [5] presented the visual product identity of selected models of the Saab Automobile range of production and concept, which studied and compared the identity of the company's products as experienced internally within the company and externally by target customers. Karjalainen [17] presented the key aspects of creating an affective and believable story for a brand and expressing it through design. Especially product attributes like shape grammar, color and texture can be studied and improved. A method was developed for encoding the key elements of a brand (i.e. Toyota, Apple, Nokia) into a repeatable language which can be used to generate products consistent with the brand (i.e. tea flask, watch, razor).

In the next section, we perform our method following the approach of Kajalainen [17]. This approach aims at studying customers' perception to product visual form and to understand the connection of the semantic adjectives with the design elements. Therefore it enables to connect the identity expression to product parameters.

\section{METHOD AND RESULTS}

This section describes an experiment led in the sector of bags design. The following method is the one described in Kajalainen [17]. According to the objectives of this research, initially, global evaluation of brand identity to semantics and presence of design elements is performed. Then, the perceived message according to what is expressed in product advertising is validated. Thai and French perceptions are compared for further improving the design expression through specific design elements.

This research approach of the design process was focused on the analysis of customers' perception after the detailed design of the product. It includes 2 phases. The first phase aims to explore the customers' perception to product visual form of luxurious brand (see part A). The second phase aims to explore the design elements with express brand identity of luxurious brand (see part B). Results from semantic analysis have been applied for translating the perceptions, sensation and preferences of the customer. Product Semantics have been used in the study to evaluate how products are perceived. This approach followed the following steps:

\section{A. How to explore the customers' perception of product visual form}

This phase aims to explore the customer perception to product visual form of luxury brand. The method included the following steps:

1) Definition of sample bags: The experiment focused on a French brand. A sample of 15 images of bags from a unique luxury brand was used, which was limited on same color and texture.

2) Definition of semantic adjectives: The adjective words were collected from magazines and websites of luxury brand and were chosen by fashion experts. A list of 20 words (opposite adjectives) was proposed. The following list of semantic adjectives was established: masculine-feminine, original-traditional, elegancefunctional, spacious-compact, serene-dynamic, luxuriousbasic, provincial-urban, chic-comfortable, simplecomplex, modern-classic.

3) Definition of the questionnaire: The questionnaire interprets images of bags and a semantic scale that consists of two opposite adjectives by a scale as shown in Fig. 1 . The scale is a 5 points Lickert scale going from -2 to 2 (see Fig. 1). The questionnaire also interprets open question for selecting elements of bag related with semantic adjectives. The questionnaire is used both for measuring semantics and examining the link between semantics and elements of bags. The questionnaire was pointed on paper data from interviews Thai and French peoples. 


\begin{tabular}{|c|c|c|c|c|}
\hline objective & Scale & objective & Number 1 & Elements? \\
\hline masculine & $+\quad+$ & feminine & & \\
\hline original & $+++1+$ & traditional & & \\
\hline elegance & $+5+1+1$ & functional & & \\
\hline spacious & $+1+1+1$ & compact & & \\
\hline serene & $+1+1$ & dynamic & & \\
\hline lusurious & $++1+1$ & basic & & \\
\hline provincial & ++++ & urban & & \\
\hline chic & $++1+1$ & comfortable & & \\
\hline simple & $++5+$ & complex & & \\
\hline modern & $++1+$ & classic & & \\
\hline
\end{tabular}

Fig. 1. The example of questionnaire

4) Definition of the people sample: This research focus on perception of Thai and French people. The people sample is shown in table I.

TABLE I

THE TABLE OF PEOPLE SAMPLE

\begin{tabular}{|c|c|c|}
\hline & French & Thai \\
\hline Male & 10 & 10 \\
\hline Female & 14 & 12 \\
\hline All & 24 & 22 \\
\hline
\end{tabular}

5) Data analysis: This step consisted of the interpretation data from the questionnaire and data analysis by using STATBOX software.

The evaluation started by interpreting the point on semantic scale line. Data were summarized before the analysis by calculating the average value of semantic adjectives for each bag as shown in table II. STATBOX enables to process a statistical analysis with several tools. This analysis was done with the principal components analysis (PCA). PCA is a technique used to reduce multidimensional data sets to lower dimensions for analysis. PCA is mostly used as a tool in expl oratory data analysis and for making predictive models. STATBOX shows the result that enable to visualize through a PCA mapping which bag act on which semantic adjectives.

TABLE II

THE TABLE OF AN AVERAGE VALUE OF SEMANTIC ADJECTIVE IN EACH BAG

\begin{tabular}{|c|c|c|c|c|}
\hline Bag & $\begin{array}{c}\text { Masculine - } \\
\text { Feminine }\end{array}$ & $\begin{array}{c}\text { Original - } \\
\text { Traditional }\end{array}$ & $\begin{array}{c}\text { Elegance - } \\
\text { Functional }\end{array}$ & $\cdots$ \\
\hline No.1 & 0.7000 & 0.8682 & 0.5409 & \\
\hline No.2 & 1.1261 & 0.3174 & 0.3435 & \\
\hline No.3 & 1.5000 & -0.1391 & -0.3000 & \\
\hline$\ldots$ & & & & \\
\hline
\end{tabular}

6) Results of PCA: The results of the emotional evaluation of the customers' perception to product visual form revealed that the whole bags sample can be classified as shown in Fig. 2. Interpretation and discussion of these results will be detailed in section IV.

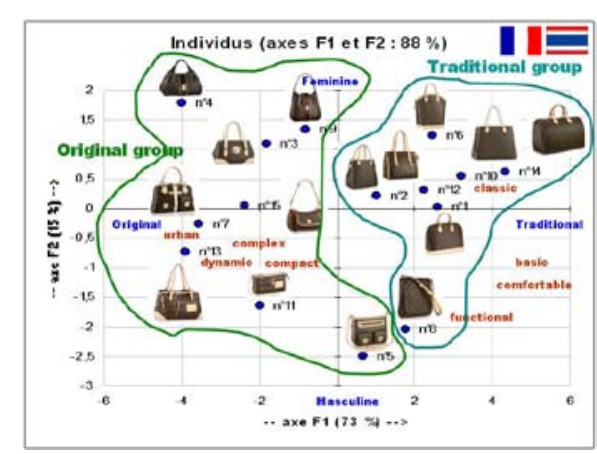

a) Thai and French people

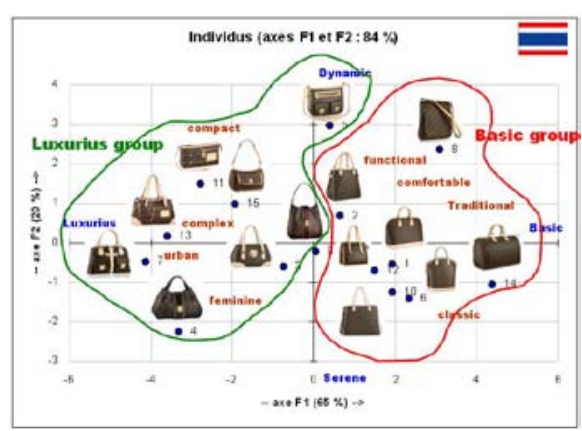

b) Thai people

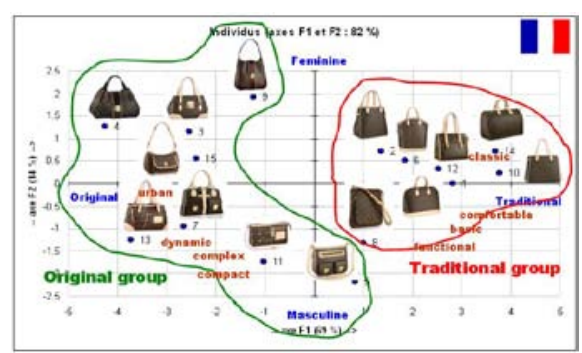

c) French people

Fig. 2. PCA mapping results

B. How to explore the design elements that express brand identity

This phase aims to study the design elements that express the brand identity of luxury brand. The results from customers' perception were translated in terms of design rules. This approach included the following steps:

1) Definition of design elements: This step is the classification of the features (design elements), which can be classified in 5 categories: Handle, Handle Tab, Lock, Zip and pocket as shown in Fig. 3.

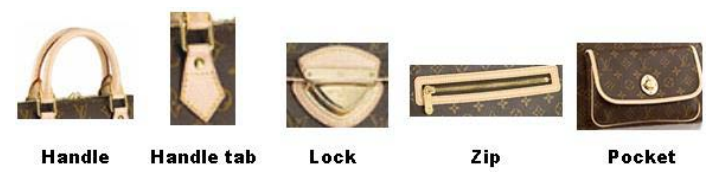

Fig. 3. Example of design element 
2) Data analysis: Data analysis of this phase is the same as in the first phase. This step consists of interpretation design elements data from the questionnaire and data analysis by using STATBOX software.

This step consists of interpreting the design elements corresponding to the semantic adjectives. This is done by assigning a significance level to the design elements with semantic adjectives. Three levels are used.

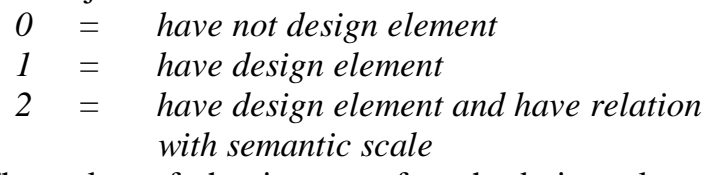

The value of the impact of each design element received the value from interpretation of each design elements. It must multiply with the value of point on semantic scale. The model of the value of the impact of each design is presented in equation 1 .

$$
\text { Score }=L \times V
$$

when, $L=$ significance level of the design element $V=$ the value of point on semantic scale

We summarize the data before analysis by average value of the impact of each design element on each feature as shown in table III. In terms of data analysis, STATBOX software is used processing in the same manner as in the first phase. Results are visualized through PCA mapping.

TABLE III

THE TABLE OF AN AVERAGE VALUE OF THE IMPACT OF EACH DESIGN ELEMENT ON EACH FEATURE

\begin{tabular}{|c|c|c|c|c|}
\hline & $\begin{array}{c}\text { Masculine - } \\
\text { Feminine }\end{array}$ & $\begin{array}{c}\text { Original - } \\
\text { Traditional }\end{array}$ & $\begin{array}{c}\text { Elegance - } \\
\text { Functional }\end{array}$ & $\cdots$ \\
\hline Handle (1) & 0.07188 & 0.18145 & 0.07275 & \\
\hline Handle (2) & 0.08435 & 0.03391 & 0.01536 & \\
\hline Handle (3) & 0.18696 & 0.01275 & -0.00464 & \\
\hline Handle tab & -0.11710 & -0.12957 & 0.15942 & \\
\hline Lock & -0.04928 & 0.02203 & 0.04580 & \\
\hline ... & & & & \\
\hline
\end{tabular}

3) Results of PCA: The results showing the linked between design elements and the expression of set of brand identity are shown in Fig. 4. Interpretation and discussion of these results will be detailed in section IV.

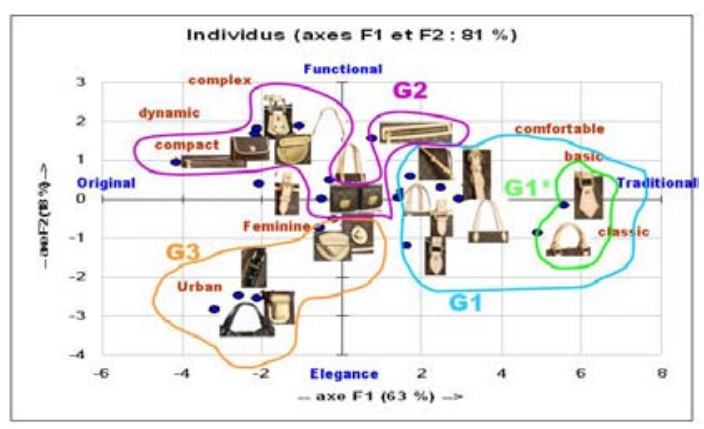

Fig. 4. PCA mapping of design element

\section{DISCUSSION}

In this part the results presented in part III are discussed.

\section{A. Explore the customers' perception of product visual form}

The customers' perception of both Thai and French is shown in Fig. 2a. The semantic adjectives can be clustered in two groups. The first group can be defined as "Traditional". This is associated to complementary emotions like classic, basic and comfortable. The second one can be defined as "Original". This is associated to urban, complex and dynamic.

1) Traditional group: The shapes and visual forms of products in this group are basic and classic. They are not affected by changes in fashion. They are more comfortable and more practical for users because of their simple design with necessary function. The design has existed or been used for a long time and expressed the brand identity.

2) Original group: The products in this group are luxurious and more expensive. They are more decorated with variety of design elements. The shapes and visual forms are modern. They usually look more attractive and fashionable because of putting more design elements on the product. The product life cycle in the market is quite short.

Luxury brands are brands whose ratio of functional utility to price is low while that of intangible utility to price is high. The advertising of luxurious brand demonstrates the product to people by their luxury, elegance and classic [18][19]. Such brand has characteristics like consistent premium quality, a heritage of craftsmanship, a recognisable style or design, a limited production run of any item to ensure exclusivity, an element of uniqueness and an ability to keep coming up with new designs when the category is fashion-intensive.

According to our results, French perception illustrates the same tendency as expressed in the most customers' perception. That is, for French perception, it can obviously distinguish the traditional group from the original group. Traditional group involves some characteristics in advertising such as a heritage of craftsmanship, basic and classic style. And, original group involves some such as a unique design element and a fashionable design. On the other hand, Thai perception illustrates similar tendency as expressed in the most customers' perception. But, for Thai perception, groups are not obviously distinct as much as in French perception. They also focus on luxury and basic style. The perceived message from both Thai and French according to what is expressed in product advertising, but in different point of views. Note that these are significant for further improving the design process. 
B. Explore the design elements that express brand identity

We classified the design elements in 3 groups (see Fig. 3) :

1) G1 (Brand identity): It is easy to recognize a brand by design elements (i.e. handle and handle tab) of product in this group. In particular, brand identity is expressed by its luxury and classic.

The subgroup $\left(\mathrm{G} 1^{*}\right)$ can be observed. We call this subgroup as "Strong brand identity". For this subgroup, the values of semantic adjectives which are to recognize a brand are more distinct than the others.

2) G2 (Added function): Products in this group have design elements which assign more functional utility (e.g. pocket, zip, etc.). When these design elements are added, the functional utility is increased.

3) G3 (Added detail or accessory): The design elements of product in this group can be developed from previous design elements, or they can be created new design elements. However, their brand identity must be kept. When putting more design elements (i.e. added detail and more decoration) on the product, the intangible utilities, such as luxury, elegance and attraction, are increased.

The results obtained by data analysis enable to visualize the semantic position of products and how this position fits the values of the brand. We can apply for the new product development process in two directions: by adding function and by adding detail or accessory to product. These results also vary depending on the population who assessed the images of bags. It is also proved that the brand identity is visible through intrinsic design element used for the bags. This conclusion should be taken into account when designing new models' ranges.

\section{CONCLUSION}

This research proposed how to explore the customers' perception to product visual from. It was based on a semantic differential method in the sector of bag design. It integrated values in order to examine their predictive potential on the semantic preferences and further choose design elements. Results from semantic analysis have been applied for translating the perceptions, sensation and preferences of the customer. Product Semantics have been used in the study to evaluate how products are perceived. This approach will lead further study in order to integrate with other approaches such as QFD (Quality Function Deployment) to assist designers in identifying customer requirement and design characteristics, and also help achieve an effective evaluation of the final design solution.

\section{REFERENCES}

[1] D. A. Norman, Emotional Design: Why We Love (or Hate) Everyday Things, Basic Books, New York, 2004.

[2] N. Crilly, J. Moultrie and P. J. Clarkson, "Seeing things: consumer response to the visual domain in product design", Design Studies, vol. 25, No. 6, pp. 547-577, 2004.

[3] M. E. Kasarda, J. P. Terpenny, D. Inman, K. R. Precoda, J. Jelesko, A. Sahin and J. Park, "Design for adaptability (DFAD) - a new concept for achieving sustainable design", Robotics and Computer-Integrated Manufacturing, vol. 23, pp. 727-734, 2007.

[4] T. M. Karjalainen and A. Warell, "Do You Recognise This Tea Flask? Transformation of brand-specific product identity through visual design cues", presented at the International Design Congress - IASDR 2005, Taiwan, 2005.

[5] A. Warell, C. Fjellner and J. Stridsman-Dahlström, "Visual Product Identity: Understanding identity perceptions conveyed by visual product design", presented at the 5th International Conference on Design \& Emotion 2006, Sweden, 2006.

[6] T. M. Karjalainen, "Strategic Brand Identity and Symbolic Design Cues", presented at the 6th Asian Design International Conference, Japan, 2003.

[7] K. Choi and C. Jun, "A systematic approach to the Kansei factors of tactile sense regarding the surface roughness", Applied Ergonomics, vol. 38, pp. 53-63, 2007.

[8] M. Nagamachi, Kansei Engineering, Kaibundo Publishing, Tokyo, 1989.

[9] R. Cappetta, P. Cillo and A. Ponti, "Convergent designs in fine fashion: An evolutionary model for stylistic innovation”, Research Policy, vol. 35, pp. 1273-1290, 2006.

[10] H. C. Chang, H. H. Lai and Y. M. Chang, "Expression modes used by consumers in conveying desire for product form: A case study of a car", International Journal of Industrial Ergonomics, vol. 36, pp. 3-10, 2006.

[11] D. McDonagh, A. Bruseberg and C. Haslam, "Visual product evaluation: exploring users' emotional relationships with products, Applied Ergonomics, vol. 33, pp. 231-240, 2002.

[12] C. Bouchard, D. Lim and A. Aoussat, "Development of a KANSEI ENGINEERING SYSTEM for Industrial design: Identification of input data for KES”, presented at the 6th Asian Design International Conference, Japan, 2003.

[13] S. Schutte and J. Eklund, "Design of rocker switches for work-vehicles - an application of Kansei Engineering”, Applied Ergonomics, vol. 36, pp. 557-567, 2005.

[14] M. Beverland, J. Napoli and A. Lindgreen, "Industrial global brand leadership: A capabilities view”, Industrial Marketing Management, vol. 36, pp. 1082-1093, 2007.

[15] C. Kohli, L. Leuthesser and R. Suri, "Got slogan? Guidelines for creating effective slogans”, Business Horizons, vol. 50, pp. 415-422, 2007.

[16] J. P. McCormack, J. Cagan and C. M. Vogel, "Speaking the Buick language: capturing, understanding, and exploring brand identity with shape grammars”, Design Studies, vol. 25, no. 1, pp. 1-29, 2003.

[17] T. M. Karjalainen, "It Looks Like a Toyota: Educational Approaches to Designing for Visual Brand Recognition”, International Journal of Design 2007, vol. 1, no. 1, pp. 6781, 2007.

[18] www.louisvuitton.com

[19] www.purseblog.com/louis-vuitton/ 